\title{
Correction to: Moral Uncanny Valley: A Robot's Appearance Moderates How its Decisions are Judged
}

\author{
Michael Laakasuo $^{1}$ (D) Jussi Palomäki ${ }^{1}$ D $\cdot$ Nils Köbis $^{2}$
}

Published online: 25 March 2021

๑) Springer Nature B.V. 2021

\section{Correction to: International Journal of Social Robotics https://doi.org/10.1007/s12369-020-00738-6}

Please find below the correct versions of two figures published in https://doi.org/10.1007/s12369-020-00738-6.
Figure 2, Study 1 correct Fig. 2.

Figure 3, Study 2 correct Fig. 3.

The original article can be found online at https://doi.org/10.1007/ s12369-020-00738-6.

Jussi Palomäki

jussi.palomaki@helsinki.fi

1 University of Helsinki, Helsinki, Finland

2 Max Planck Institute for Human Development, Center for Humans \& Machines, Berlin, Germany 


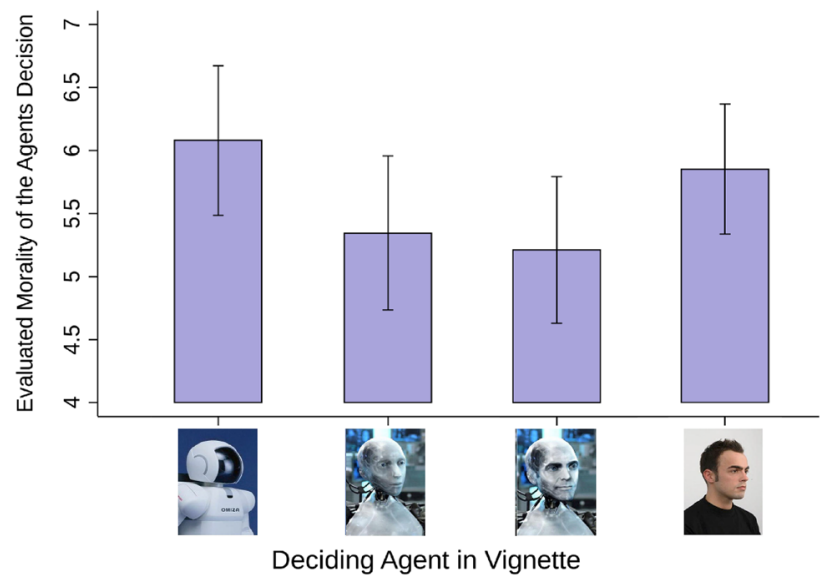

Fig. 2 Results of Study 1. The quadratic contrast shape is similar to the Uncanny Valley shape proposed by Mori [49]; error bars are $95 \%$ CIs

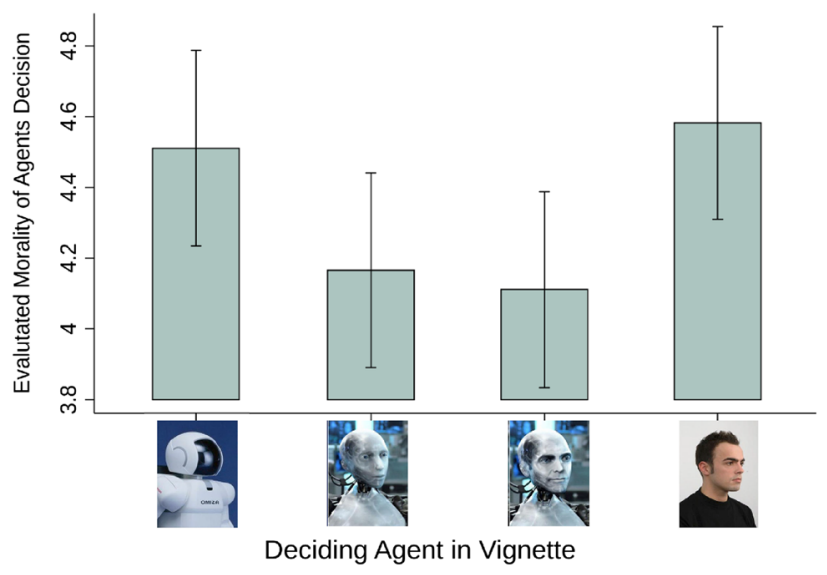

Fig. 3 Results of Study 2; error bars are 95\% CIs. Evaluated Morality of Agents refers to the aggregate score of perceived morality of the agent's choices across 4 moral dilemmas

Publisher's Note Springer Nature remains neutral with regard to jurisdictional claims in published maps and institutional affiliations. 